\title{
REPLICATING THE DOW JONES INDUSTRIAL AVERAGE
}

\author{
Jacky Lin \\ Genevieve C. Selden \\ John B. Shoven \\ Clemens Sialm \\ Working Paper 28528 \\ http://www.nber.org/papers/w28528 \\ NATIONAL BUREAU OF ECONOMIC RESEARCH \\ 1050 Massachusetts Avenue \\ Cambridge, MA 02138 \\ March 2021
}

The authors thank Gary Smith of Pomona College for help with historical return series. Clemens Sialm is an independent contractor at AQR Capital Management, LLC. The views expressed herein are those of the authors and do not necessarily reflect the views of the National Bureau of Economic Research.

At least one co-author has disclosed additional relationships of potential relevance for this research. Further information is available online at http://www.nber.org/papers/w28528.ack

NBER working papers are circulated for discussion and comment purposes. They have not been peer-reviewed or been subject to the review by the NBER Board of Directors that accompanies official NBER publications.

(C) 2021 by Jacky Lin, Genevieve C. Selden, John B. Shoven, and Clemens Sialm. All rights reserved. Short sections of text, not to exceed two paragraphs, may be quoted without explicit permission provided that full credit, including (C) notice, is given to the source. 
Replicating the Dow Jones Industrial Average

Jacky Lin, Genevieve C. Selden, John B. Shoven, and Clemens Sialm

NBER Working Paper No. 28528

March 2021

JEL No. G10

\section{ABSTRACT}

The Dow Jones Industrial Average has historically been the most quoted stock index in the United States. It has several unique features. It uses price weights, it ignores cash dividend payments, and it also treats stock dividends, rights issues, and other corporate actions inconsistently. We show that price indices which use alternative weighting methods and more systematic inclusion criteria perform similarly to the Dow. However, ignoring cash and stock dividends underestimates the long-run returns earned by stock market investors dramatically. If the DJIA had consistently adjusted for dividends and other corporate actions since 1928, the index would have closed at 1,113,047 instead of 28,538 points at the end of 2019.

\section{Jacky Lin}

Stanford University

757 Campus Drive

Stanford, CA 94305

jackylin@stanford.edu

Genevieve C. Selden

Cornerstone Research

gcselden1@gmail.com
John B. Shoven

Department of Economics

Stanford University

Landau Economics Building

579 Jane Stanford Way

Stanford, CA 94305

and NBER

shoven@stanford.edu

Clemens Sialm

University of Texas at Austin

McCombs School of Business

2110 Speedway; B6600

Austin, TX 78712-1276

and NBER

clemens.sialm@mccombs.utexas.edu 


\section{Introduction}

The Dow Jones Industrial Average (DJIA) is one of the most quoted stock market indices in the world. The index is often perceived to reflect the performance of the U.S. stock market. This paper replicates the DJIA since 1928 and investigates whether the index is indeed representative of the performance of the U.S. stock market.

Charles Dow, one of the founders of Dow Jones \& Co., created the first stock market index in 1884. He began with 11 large stocks, most of them railways. The Industrial Average was first published on May 26, 1896. It included all 12 industrial companies listed on the New York Stock Exchange, as industrial and manufacturing firms were increasing in importance relative to the previously dominant railroads. Its base value was 40.94 points. ${ }^{1}$ In 1916 , the Industrial Average was increased to 20 stocks, and in October 1928, the number was expanded to 30 securities. Also in 1928, the index providers began calculating the average with a special divisor to avoid distortions when constituent companies split their shares or when one company was substituted for another. In 2012, S\&P Dow Jones Indices LLC was launched as a joint venture between S\&P Global, the CME Group, and News Corp. They maintain stock market indices as benchmarks and as the basis of investable products, such as exchange-traded funds (ETFs), mutual funds, and derivatives. $^{2}$

The DJIA is a price-weighted index that measures the performance of some of the largest U.S. companies. The 30 companies currently in the DJIA are large, but not necessarily “industrial.” The

\footnotetext{
1 The Dow Jones Rail Average, whose name was changed in 1970 to the Transportation Average, separately represented railroad companies. The Dow Jones Utility Average was founded in 1929.

2 See Pierce (1996), Siegel (1998), and Shoven and Sialm (2000). The official webpage of S\&P Dow Jones Indices includes additional information about the methodology and history of the DJIA (www.spdji.com/djia).
} 
companies represent every important sector in the stock market (except transportation companies and utilities). Membership in the DJIA is not determined by purely quantitative criteria. Instead, companies are included in the DJIA only if they have an excellent reputation, demonstrate sustained growth, and are of interest to a large number of investors. Companies should be incorporated and headquartered in the U.S. and a plurality of the revenues should be derived from the U.S. Reconstitutions to the index are made as-needed and are relatively rare. ${ }^{3}$ Table A.1 in the Appendix lists the companies in the DJIA at the end of December 2019.

The DJIA has several unique features. First, each company in the index is weighted by the price of its stock. The importance of each company in the index does not depend on the total market capitalization (a measure of the size) of the company. Instead, a highly priced stock has a higher weight than a lower priced stock. Each time a company in the DJIA splits, the weight of this company decreases because the stock price falls by the ratio of the split.

Second, the constituents of the DJIA are not representative of the market as a whole. The 30 firms are chosen among large-capitalization firms to represent different industries, but they are not chosen according to fixed pre-determined rules. In particular, the DJIA is not an index of the 30 largest companies in the United States. Furthermore, a more representative index would include a much larger number of companies.

Third, the index has treated corporate actions, such as stock dividends and rights issues in an inconsistent way over its long history. While the index has typically adjusted its divisor for stocks

\footnotetext{
${ }^{3}$ This characterization is obtained from S\&P Dow Jones (2021). The document includes additional information on the index construction.
} 
splits, it has frequently not adjusted it for stock dividends, which are conceptually identical to stock splits. For example, the index providers announced in 1947 that they would only adjust the divisor for large stock dividends that would change the average by more than one point. Similarly, the index also ignored most rights issues, which were fairly popular in the early part of our sample period. Although each individual corporate action may not have a substantial impact on the index on a daily basis, these omissions can create a significant downward bias over the longer term.

Fourth, in the early part of our sample, the DJIA also exhibits some discrepancies due to an infrequent adjustment of the divisor and due to coarse rounding. For example, stock splits in the 1920s were incorporated in the divisor with a date discrepancy of several months. Furthermore, the divisor from 1935 to 1947 was rounded to only one significant digit, which could generate discrepancies due to rounding of as much as 0.4 percent of the level of the DJIA for each divisor change. These discrepancies will not systematically bias the index as each of these discrepancies is about equally likely to increase or decrease the value of the DJIA.

Fifth, the DJIA is not a total return index because it excludes dividend distributions, as emphasized previously by Clarke and Statman (2000) and Shoven and Sialm (2000). Dividends account for a considerable portion of returns to shareholders in the long run. If a stock index is used to gauge the return earned by market participants over long periods of time, a total return index would be a far superior representation. The difference between a total return index and a price return index becomes noticeable for periods as short as a quarter. Over shorter periods, the two types of indices are similar. Hence, a total return index dominates a price return index in gauging the returns experienced by stockholders. 
We find that the price weighting and the selection of the index constituents do not have a significant impact on the long-term performance of large-capitalization stocks in the U.S. For example, the arithmetic average price return of the DJIA from 1929-2019 amounts to 6.97\% per year, whereas the corresponding average returns are $6.78 \%$ for a value-weighted index of the constituents of the DJIA and 6.68\% for a value-weighted index of the largest 30 firms publicly traded on U.S. stock exchanges (i.e., Big 30 index). The returns for these alternative indices are not statistically significantly different from the return on the DJIA. We only find reliably superior performance for equal-weighted indices. For example, an equal-weighted index of the 30 DJIA constituents with annual rebalancing has an average price return of 7.68\% over our sample period.

The inconsistent treatment of stock dividends, rights issues, and other corporate events has a moderate impact on value of the DJIA. Incorporating these events based on the CRSP stock price database increases the value of the DJIA by approximately $15.3 \%$ over our entire sample period (i.e., the DJIA would have been at 32,914 instead of 28,538 points at the end of December 2019).

In contrast to weightings and corporate actions, ignoring cash dividends results in a dramatic under-estimation of the performance of stock markets over the long run. If all cash dividends since October 1928 had systematically been reinvested in the constituents of the DJIA, the priceweighted DJIA would have closed at the end of December 2019 at 1,113,047 points instead of just 28,538 points. Thus, the index value would have been almost 40 times higher if reinvested dividends had been included. The average annual return is $11.28 \%$ with dividends and just $7.11 \%$ without dividends (using our replicated index). Since few firms in the DJIA pay dividends on a 
typical day, dividends do not play an important role when judging daily index returns. However, ignoring dividends has a dramatic impact over long horizons.

The literature on the merits and failings of the DJIA is almost as old as the index itself. Comer (1952), Hartman and Decker (1953), Shaw (1955), Milne (1966), and Rudd (1979) discuss the role of stock splits, the weighting methods, and the industry composition of the DJIA. Hartman and Decker (1953) identify a bias in the index due to stock dividends and rights issues. They also suggest that the weighting should not be adjusted after a stock split since a split occurs "at the time the particular stock is at the top part of its historical influence on the average” (p. 45). An upward bias results from the fact that the Milne (1966) computes the performance of alternative indices based on value, price, and equal weights. He suggests that "the DJIA should take advantage of the advent of the computer to make the more elaborate calculations necessary for a logical and consistent stock price index” (p. 83).

The importance of dividend payments for the DJIA has been discussed by Clarke and Statman (2000) and Shoven and Sialm (2000). ${ }^{4}$ Both papers compute the value of the DJIA incorporating reinvested dividends. This paper updates the return of the DJIA including dividend payments through 2019. We investigate the impact of stock dividends, rights issues, and other corporate actions. Finally, we are now able to compute daily return indices. ${ }^{5}$ This allows us to replicate the DJIA more precisely than earlier studies. The official DJIA is practically useless for gauging the long-term performance of equity markets. Our total return indices rectify this problem.

\footnotetext{
${ }^{4}$ Hartzmark and Solomon (2019, 2020) analyze in two influential papers the implications of the disconnect between dividends and capital gains. They show that investors' perception of performance is biased because major indices ignore dividends.

${ }^{5}$ CRSP only started to publish daily stock returns prior to 1962 in 2006.
} 


\section{Index Construction}

In this section we discuss the construction of price-, value-, and equal-weighted indices and demonstrate how indices need to be adjusted after index membership changes and after corporate actions, such as stock splits, rights issues, and cash dividend payments.

\section{A. Price-Weighted Index}

The DJIA is a price-weighted index. The actual value of the index can be determined using the following formula:

$$
D J I A_{t}=\frac{1}{d_{t}} \sum_{i} P_{i, t} .
$$

The price of the stock of company $i$ at time $t$ is denoted by $P_{i, t}$, and the divisor is given by $d_{t}$. The divisor of the DJIA originally equaled the number of companies in the index. Since 1928, the divisor has changed each time the composition of the index was modified, or a member stock splits, or a member pays a large stock dividend. These divisor changes ensure that these events do not cause a discontinuity in the value of the index. The divisor was 0.14744568353097 on December 31, 2019. Table A.1 in the Appendix lists the 30 companies in the index at the end of December 2019. Summing the stock prices in Table A.1 and dividing by the divisor gives the value of the DJIA on this day, which was 28,538.44 points (i.e., 4207.87/0.14744568353097). Boeing (BA) had the highest weight and Pfizer (PFE) the lowest weight. Apple's (AAPL) weight in the DJIA was less than half its relative market capitalization. The DJIA corresponds to the value of a portfolio that is invested in $1 / d$ shares in each company in the DJIA. As of December $31^{\text {st }}, 1 / \mathrm{d}$ was around 6.78, which is the number of shares of each of the 30 stocks that equals in value to the official DJIA. Investors trying to replicate the performance of the DJIA average would need to rebalance their portfolio whenever the divisor changes. 


\section{B. Divisor Changes}

To correctly capture the total performance for investors in a price-weighted index, one needs to adjust the index for different events: First, the portfolio weights need to be changed whenever the index provider swaps constituents. The DJIA achieves this by changing the divisor so that the level of the index at the close on the day prior to the swap with the old constituents (i.e., $i \in\{O\}$ ) is identical to the index with the new constituents (i.e., $i \in\{N\}$ ). The new divisor $d_{t+1}$ can be computed based on the following equation:

$$
D J A_{t}=\frac{1}{d_{t}} \sum_{i \in\{O\}} P_{i, t}=\frac{1}{d_{t+1}} \sum_{i \in\{N\}} P_{i, t}
$$

Second, the divisor needs to be adjusted when a stock splits or when a stock distributes a stock dividend. ${ }^{6}$ Suppose a company does a two-for-one split of stock $i$ taking place on date $t+1$ (i.e., $\left.s_{i, t+1}=2\right)$. In this case, the new divisor $d_{t+1}$ can be computed from the following equation:

$$
D J I A_{t}=\frac{1}{d_{t}} \sum_{i \in\{O\}} P_{i, t}=\frac{1}{d_{t+1}} \sum_{i \in\{O\}} \frac{P_{i, t}}{s_{i, t+1}}
$$

Third, the divisor also needs to be adjusted after rights issues, spinoffs, and stock distributions. For example, suppose stock $i$ makes on date $t+1$ one of these distributions that has a dollar value of $D_{i, t+1}$. In this case, the price of the stock should decrease by $D_{i, t+1}$ on the ex day. The new divisor $d_{t+1}$ can then be derived from the following equation: ${ }^{7}$

\footnotetext{
${ }^{6}$ A stock dividend is a dividend that is made in shares rather than in cash. For example, a stock dividend of 5\% requires the firm to issue 0.05 shares for every share owned by existing shareholders, so the owner of 100 shares would receive 5 additional shares. Thus, stock dividends are conceptually identical to stock splits.

${ }^{7}$ This adjustment method allows the index provider to determine the divisor and the index value on the day prior to the ex-dividend day. It appears that this is the method that the DJIA uses to adjusted for special dividends. An alternative adjustment would be to use the following formula: $D J I A_{t+1}=\frac{1}{d_{t}} \sum_{i \in\{O\}}\left(P_{i, t+1}+D_{i, t+1}\right)=$ $\frac{1}{d_{t+1}} \sum_{i \in\{O\}} P_{i, t+1}$. In this case, one would only be able to compute the divisor at the close on the ex-dividend day.
} 


$$
D J I A_{t}=\frac{1}{d_{t}} \sum_{i \in\{O\}}\left(P_{i, t}\right)=\frac{1}{d_{t+1}} \sum_{i \in\{O\}}\left(P_{i, t}-D_{i, t+1}\right)
$$

\section{Index Rate of Return}

The daily rate of return of the DJIA on dates without events is defined as follows:

$$
\begin{aligned}
R_{t+1} & =\frac{D J I A_{t+1}}{D J I A_{t}}-1=\frac{\frac{1}{d_{t+1}} \sum_{i} P_{i, t+1}}{\frac{1}{d_{t}} \sum_{i} P_{i, t}}-1=\frac{\sum_{i} P_{i, t+1}}{\sum_{i} P_{i, t}}-1 \\
& =\sum_{i} \frac{P_{i, t}}{\sum_{j} P_{j, t}} \frac{P_{i, t+1}}{P_{i, t}}-1=\sum_{i} w_{i, t}\left(1+R_{i, t+1}\right)-1=\sum_{i} w_{i, t} R_{i, t+1} .
\end{aligned}
$$

The divisor cancels out in the first line (i.e., $d_{t}=d_{t+1}$ ) since it does not change when there are no events. The weight of a stock in a price-weighted portfolio is the relative price of the corresponding stock (i.e., $w_{i, t}=P_{i, t} / \sum_{j} P_{j, t}$ ). Thus, the return of the DJIA is simply the weighted-average price return of the index components.

After a composition change, the return of the index only reflects the performance of the new components:

$$
\begin{aligned}
R_{t+1} & =\frac{D J I A_{t+1}}{D J I A_{t}}-1=\frac{\frac{1}{d_{t+1}} \sum_{i \in\{N\}} P_{i, t+1}}{\frac{1}{d_{t}} \sum_{i \in\{O\}} P_{i, t}}-1=\frac{\frac{1}{d_{t+1}} \sum_{i \in\{N\}} P_{i, t+1}}{\frac{1}{d_{t+1}} \sum_{i \in\{N\}} P_{i, t}}-1=\frac{\sum_{i \in\{N\}} P_{i, t+1}}{\sum_{i \in\{N\}} P_{i, t}}-1 \\
& =\sum_{i \in\{N\}} \frac{P_{i, t}}{\sum_{i \in\{N} P_{j, t}} \frac{P_{i, t+1}}{P_{i, t}}-1=\sum_{i \in\{N\}} w_{i, t} R_{i, t+1} .
\end{aligned}
$$

However, returns using this alternative method generate total returns that are computed in the conventional way (i.e., $\left.R_{i, t+1}=\frac{P_{i, t+1}+D_{i, t+1}}{P_{i, t}}-1\right)$. Equation (4) instead implies slightly different total returns of $R_{i, t+1}=\frac{P_{i, t+1}}{P_{i, t}-D_{i, t+1}}-1$. 
After a split or stock dividend, the weight of the splitting stock is decreased due to the split ratio, and the return of the splitting stock is adjusted for the split ratio (i.e., $R_{i, t+1}=P_{i, t+1} /\left(P_{i, t} / s_{i, t+1}\right)-$ 1). The weight of the securities is adjusted at the end of the day prior to the split.

$$
\begin{aligned}
R_{t+1} & =\frac{D J I A_{t+1}}{D J I A_{t}}-1=\frac{\frac{1}{d_{t+1}} \sum_{i} P_{i, t+1}}{\frac{1}{d_{t}} \sum_{i} P_{i, t}}-1=\frac{\frac{1}{d_{t+1}} \sum_{i} P_{i, t+1}}{\frac{1}{d_{t+1}} \sum_{i} P_{i, t} / s_{i, t+1}}-1=\frac{\sum_{i} P_{i, t+1}}{\sum_{i} P_{i, t} / s_{i, t+1}}-1 \\
& =\sum_{i} \frac{P_{i, t} / s_{i, t+1}}{\sum_{j} P_{j, t} / s_{j, t+1}} \frac{P_{i, t+1}}{P_{i, t} / s_{i, t+1}}-1=\sum_{i} w_{i, t}\left(1+R_{i, t+1}\right)-1=\sum_{i} w_{i, t} R_{i, t+1} .
\end{aligned}
$$

Finally, the total index return including cash dividends or other distributions would correspond to the weighted average of the total return of the index components:

$$
R_{t+1}=\frac{D J I A_{t+1}}{D J I A_{t}}-1=\frac{\frac{1}{d_{t+1}} \sum_{i} P_{i, t+1}}{\frac{1}{d_{t}} \sum_{i} P_{i, t}}=\frac{\frac{1}{d_{t+1}} \sum_{i} P_{i, t+1}}{\frac{1}{d_{t+1}} \sum_{i}\left(P_{i, t}-D_{i, t+1}\right)}-1=\frac{\sum_{i}\left(P_{i, t+1}\right)}{\sum_{i}\left(P_{i, t}-D_{i, t+1}\right)}-1 .
$$

\section{E. Alternative Weighting Methods}

A value-weighted index (VWI) is constructed in the following way:

$$
V W I_{t+1}=V W I_{t} \sum_{i} w_{i, t}\left(1+R_{i, t+1}\right) \text {, where } w_{i, t}=\frac{P_{i, t-1} N_{i, t-1}}{\sum_{i} P_{i, t-1} N_{i, t-1}} .
$$

The relative market capitalization of company $i$ is denoted with $w_{i, t}$ and $N_{i, t}$ is the number of shares outstanding of stock $i$ at time $t$. A stock split does not affect the value of a value-weighted index unless it affects the holding period returns of the stock. Apple (AAPL) had, at the end of December 2019, the highest relative market capitalization of the 30 Dow-components of 15.9 percent and Travelers (TRV) had the lowest weight of 0.43 percent as shown in Table A.1. A value-weighted index corresponds to a portfolio where each asset is held in proportion to its market capitalization. ${ }^{8}$

\footnotetext{
${ }^{8}$ Some indices use float-adjusted market capitalization instead. Float-adjusted indices only count the shares that are available to investors and exclude closely held shares or shares held by governments or other companies.
} 
The changes of a value-weighted index correspond to the changes of the total market value of all the companies included in the index. Investors trying to match the index only need to adjust their portfolio when a constituent company issues new stock or repurchases shares. A price return index is based on the percentage change in the price (i.e., $R_{i, t+1}=P_{i, t+1} / P_{i, t}-1$ ), whereas a total return index includes the impact of dividend payments (i.e., $\left.R_{i, t+1}=\left(P_{i, t+1}+D_{i, t+1}\right) / P_{i, t}-1\right)$. The S\&P 500 is a prominent example of a value-weighted price return index.

An equal-weighted index (EWI) gives each of the $n$ companies in the index the same weight:

$$
E \mathrm{WI}_{t+1}=\mathrm{EWI}_{t} \frac{1}{n} \sum_{i}\left(1+R_{i, t+1}\right)
$$

The number of shares in each company that an investor would need to hold in order to replicate an equally-weighted index is proportional to $1 / P_{i, t .}$ Investors need to hold more shares in low-priced stocks such that the dollar-amount invested in each stock is identical. Investors desiring to continuously hold an equally-weighted index need to readjust their portfolio continuously by selling shares in companies that out-performed the index in the previous period and by buying shares in the companies that under-performed the index. This strategy generates considerable trading costs and tax liabilities for investments in taxable accounts. Stock splits do not affect the value of an equally weighted index and do not necessarily require any rebalancing. One way to reduce the rebalancing costs of an equal-weighted index would be to re-establish the equal weighting on a monthly, quarterly, or annual basis rather than on a daily basis. 


\section{Data Sources}

The historical values for the DJIA are retrieved from the Dow Jones Daily Industrial Index from the Wharton Research Data Services (WRDS) at the University of Pennsylvania, Yahoo Finance, and Williamson (2000). ${ }^{9}$

The membership composition and the history of divisors of the DJIA is obtained from Dow Jones (2000), the S\&P Dow Jones Indices, and the Wall Street Journal. ${ }^{10}$

Figure 1 represents the official DJIA from October 1, 1928 to December 31, 2019. The DJIA started at 240.01 points on October 1, 1928 and ended at 28,538.44 points on December 31, 2019. During the Great Depression, the Dow decreased by 89 percent from a high of 381.17 points on September 3, 1929 to a low of 41.22 points on July 8, 1932.

All company-related information is taken from the Center for Research in Security Prices (CRSP) from the WRDS website and corroborated with official company documentations. ${ }^{11}$ The returns of the risk-free rate are obtained from Ken French’s data library. ${ }^{12}$

\footnotetext{
${ }^{9}$ The data can be downloaded at: https://www.measuringworth.com/datasets/DJA/.

${ }^{10}$ An overview of the historical composition of the DJIA is available at: https://us.spindices.com/indexology/djia-andsp-500/the-changing-djia.

${ }^{11}$ The CRSP stock database excludes price data for National Cash Register Corporation (NCR) prior to 1934. CRSP's coverage of NCR begins in 1934 after NCR undergoes a reorganization. We use prices from the Wall Street Journal from 1/7/1929 to 8/14/1929 and prices from Arora, Capp, and Smith (2008) from 8/14/1929 to 5/26/1932. We thank Gary Smith for providing us with the data.

12 The data can be obtained from http://mba.tuck.dartmouth.edu/pages/faculty/ken.french/data_library.html .
} 
Figure 1: Dow Jones Industrial Average (October 1928 - December 2019)

100000

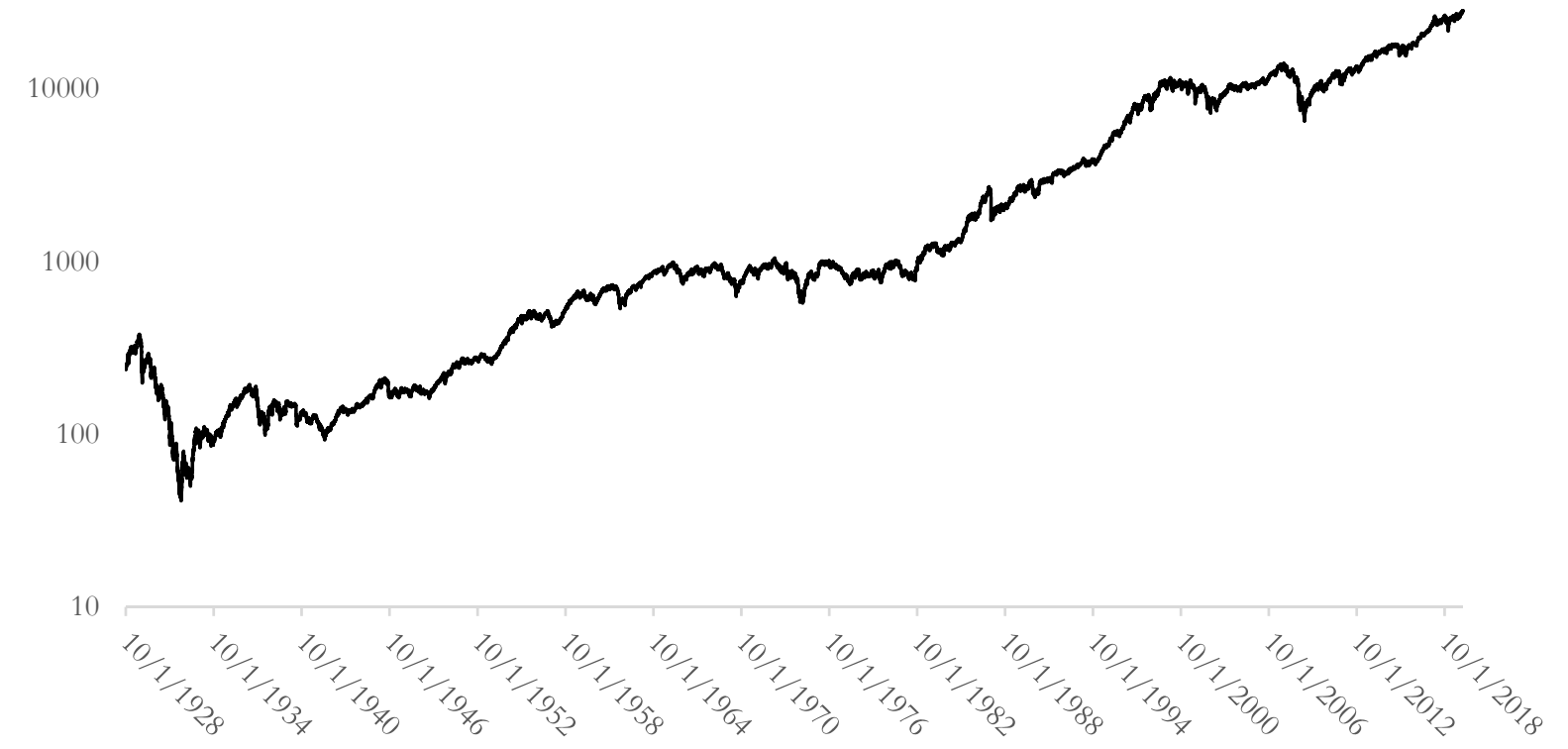

\section{Replication Discrepancies}

In this section we identify several discrepancies between the DJIA and the replication based on the CRSP database.

\section{A. Stock Splits and Stock Dividends}

Table 1 reports the corporate actions that require an adjustment in the divisor of a price-weighted price index. Stock splits are the most common actions amounting to 158 events over our sample period. All but one of these stock splits led to adjustments of the divisor of the official DJIA. ${ }^{13}$

\footnotetext{
13 On September 18, 1955, Sears Roebuck \& Company (S) had a 1\% stock dividend that is classified in the CRSP database as a stock split.
} 
Table 1: Corporate Actions that Require Adjustment in Divisor

\begin{tabular}{|c|ccc|}
\hline $\begin{array}{c}\text { Type of } \\
\text { Corporate Action }\end{array}$ & $\begin{array}{c}\text { Total } \\
\text { Actions }\end{array}$ & $\begin{array}{c}\text { Unrecorded } \\
\text { Actions }\end{array}$ & $\begin{array}{c}\text { Fraction of All Unrecorded } \\
\text { Non-Dividend Actions }\end{array}$ \\
\hline Split & 158 & 1 & $0.7 \%$ \\
Stock dividend & 105 & 81 & $59.1 \%$ \\
Rights issue & 52 & 51 & $37.2 \%$ \\
Spin-off & 26 & 1 & $0.7 \%$ \\
Non-ordinary distribution & 15 & 3 & $2.2 \%$ \\
Step in liquidation & 1 & 0 & $0.0 \%$ \\
Partial liquidation & 1 & 0 & $0.0 \%$ \\
\hline
\end{tabular}

The second-most frequent action is stock dividends, which are conceptually identical to stock splits. Over our sample period, we observe 105 stock dividends. However, only 24 of these stock dividends have been recognized by the DJIA, leading to an adjustment in the divisor. ${ }^{14}$ Historically, the DJIA has adjusted for relatively large stock dividends, but did not adjust for smaller stock dividends: The average stock dividend of DJIA components that is not accompanied by a divisor change amounts to $3.02 \%$. The failure to adjust the divisor for some stock dividends results in a downward bias in the DJIA. The inconsistent treatment of DJIA between stock splits and stock dividends and within stock dividends (between larger and smaller ones) is problematic and biases the index value downwards.

\section{B. Rights Issues and Spin-Offs}

Rights issues are also fairly frequent events that are almost always ignored by the providers of the DJIA. ${ }^{15}$ Rights issues are valuable for stock investors and ignoring these events understates the

\footnotetext{
${ }^{14}$ On December 3, 1947, Dow Jones decided that "any stock dividend, etc. that will change the averages by one or more points should be recognized by a change in divisors." Not all stock dividends are small. For example, Goodyear Tire \& Rubber's issued a 100\% stock dividend on September 11, 1951. This stock dividend would be identical to a two-for-one stock split.

${ }^{15}$ American Telephone \& Telegraph Company (ATC) issued a right offering of one share of stock for each ten shares held (purchase price \$100 per share) on September 14, 1956.
} 
performance of an index. Unlike rights issues, which are ignored, the DJIA adjusts its divisor for most spin-offs of Dow component companies.

Table 2: Corporate Actions that Require Adjustment in Divisor by Decade (Excluding Member Swaps)

\begin{tabular}{|l|ccc|}
\hline By decade: & $\begin{array}{c}\text { Total Non-Dividend } \\
\text { Corporate Actions }\end{array}$ & $\begin{array}{c}\text { Unrecorded Non- } \\
\text { Dividend Actions }\end{array}$ & $\begin{array}{c}\text { Number of Divisor Changes } \\
\text { (excluding member swaps) }\end{array}$ \\
\hline $1928-1929$ & 29 & 20 & 9 \\
$1930-1939$ & 29 & 28 & 1 \\
$1940-1949$ & 34 & 20 & 14 \\
$1950-1959$ & 70 & 39 & 31 \\
$1960-1969$ & 53 & 24 & 29 \\
$1970-1979$ & 16 & 3 & 13 \\
$1980-1989$ & 40 & 3 & 34 \\
$1990-1999$ & 50 & 0 & 50 \\
$2000-2009$ & 25 & 0 & 24 \\
$2010-2019$ & 5 & 0 & 5 \\
\hline
\end{tabular}

Table 2 shows that most of the events unrecognized by a divisor change occur prior to 1970 .

Interestingly, overall events have declined over the last two decades as firms are less likely to split their shares and execute other corporate actions.

\section{Date Discrepancies}

We also identify around a dozen discrepancies between the event dates provided by CRSP and the dates used by the DJIA to adjust the divisor. Although most of these discrepancies occur in the early part of the sample (1928-1932), some discrepancies occur as late as 2009. For example, according to the CRSP database, American Smelting (AR) performed a three-for-one stock split on December 27, 1928 and Radio Corporation (RCA) performed a five-for-one stock split on March 12, 1929. However, the DJIA adjusted the divisor for both stock splits on January 9, 1929, 
when it also replaced Victor Talking Machine with National Cash Register. Although the DJIA uses different effective dates for the stock splits, the index providers adjust the prices of the splitting companies to ensure that there are no discontinuities in the index levels.

\section{Price Discrepancies}

The prices provided in the CRSP database in some circumstances do not correspond to the prices apparently used by the index providers. ${ }^{16}$ This may be due to the fact that the DJIA and CRSP use different data providers or that prices in the CRSP database are changed retroactively. These discrepancies will typically only have a temporary impact on the level of the DJIA until the price discrepancies disappear. A permanent difference in the level of the DJIA results if the price discrepancies happen on the days the divisor is adjusted. In this case, the future divisors will all be affected by the price discrepancy.

\section{E. Rounding of Divisor}

A final discrepancy occurs due to the rounding of the divisor. The DJIA provider rounded the divisor to tenths from November 20, 1935 to May 30, 1947, to hundredths prior to November 20, 1935 and from May 30, 1947 to June 18, 1956, and to thousandths from June 18, 1956 to May 12, 1992. Since May 12, 1992, the DJIA is computed based on a divisor that includes at least eight

\footnotetext{
${ }^{16}$ On July 3, 2014, the prices provided by S\&P Dow Jones Indices for five companies do not match the prices in the CRSP database. ExxonMobil (XOM)'s provided price is 102.26, whereas XOM's CRSP price is 102.59. Similarly, price differences for the other four companies are as follows: General Electric (GE) 26.85 versus 26.86, Johnson \& Johnson (JNJ) 105.84 versus 105.42, JPMorgan (JPM) 57.13 versus 57.05, and American Express (AXP) 95.82 versus 95.84. These price discrepancies result in a single-day difference in the calculated DJIA of 0.9 Dow points when summing up the prices and dividing by the divisor.
} 
significant digits. These rounding differences have a permanent impact on the DJIA that can be economically significant. ${ }^{17}$

\section{Replicated Indices of Dow Components}

In this section we construct an alternative price-weighted price index of the Dow components that correctly adjusts for corporate events such as stock splits, stock dividends, rights issues, and spinoffs based on the CRSP database.

\section{A. Replication using CRSP Data}

We compute the value of a price-weighted index of the Dow components since 1928 using the CRSP database. We consistently adjust for stock splits, stock dividends, rights issues, and spinoffs using the information provided by the CRSP database. We set the initial value of the replicated index equal to the "official” Dow at the beginning of the sample period, which is 240.01 . We refer to this replicated Dow Jones index as the DJIA-R, whereas the official Dow Jones is simply abbreviated by DJIA.

Figure 2 contrasts the values of the official and the replicated DJIA from October 1928 to December 2019. Although the two indices closely track each other, the replicated index exhibits a higher overall value as the missed stock dividends and right issues bias the value of the official DJIA downwards. At the end of December 2019, the DJIA closed at a value of 28,538.44 points,

\footnotetext{
${ }^{17}$ On May 16, 1947, Kodak performed a five-for-one stock split and the divisor changed from 13.3 to 12.2. However, the unrounded divisor should have been 12.18495326 using an initial divisor of 13.3. The index value without rounding the divisor would have been 165.17 points, which is 0.12 percent higher than the actual DJIA of 164.97. The maximum rounding error with a divisor of 12.2 would be around 0.4 percent (i.e., 0.05/12.2).
} 
whereas the replicated DJIA, with all corporate events accounted for, closed at 32,913.65 points.

Overall, the official DJIA is biased downward by 15.3 percent.

Figure 2: DJIA and Replicated DJIA based on CRSP Database

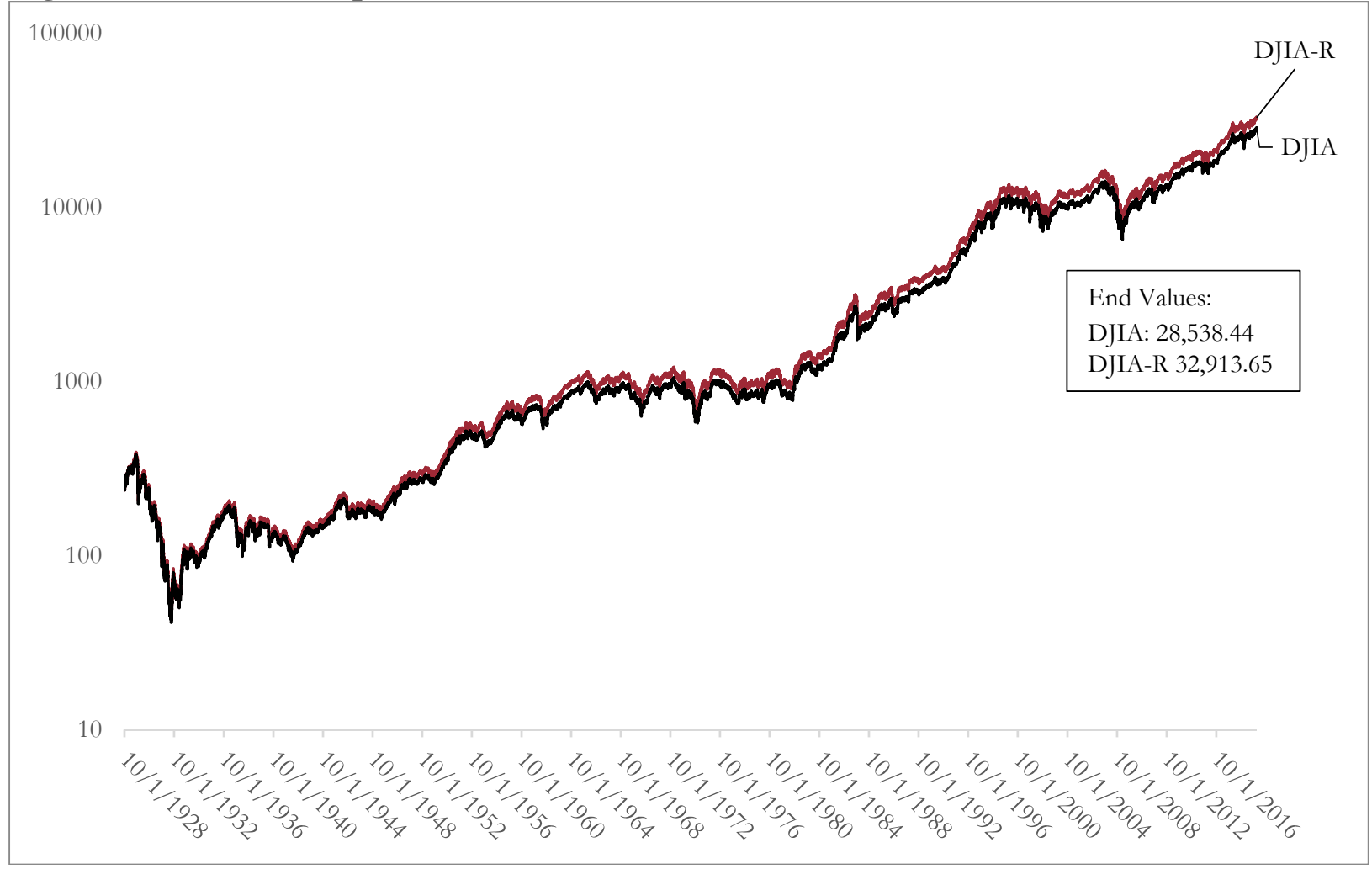

To test whether the performance difference between the official and the replicated DJIA is statistically significant, we compute the annual price returns of the two indices and test whether the mean returns are significantly different using a paired $t$-test. The $p$-value of the test is 0.0004 , which indicates that the return difference is statistically significant. We also find that the replicated index outperforms the official DJIA in 60 of the 91 years covering our sample period. ${ }^{18}$

\footnotetext{
18 The annual mean returns, standard deviations, and $p$-values exclude the partial year of 1928 that occurs in our sample. Thus, these calculations include only values from the first trading day of 1929 to December 31, 2019.
} 


\section{B. Decomposition of Index Discrepancies}

To investigate which of the event types explain the difference between the official and replicated DJIA, we sequentially adjust our replicated index for various corporate actions. The time series of the percentage difference are reported in Figure 3. The orange curve shows the overall percentage discrepancy, which amounts to 15.3 percent at the end of the sample period. Most of this discrepancy occurs before 1960 as stock dividends and rights issues, which have been typically ignored by the providers of the DJIA, but they are less common in recent decades.

The discrepancy between the official and our replicated DJIA shrinks to 5.5 percent if we exclude stock dividends, to 1.4 percent if we additionally exclude rights issues, and to 0.06 percent if we also exclude all other corporate events. In contrast to these events, adjusting for date discrepancies actually reduces the value of the replicated index by 1.6 percent.

Overall, the downward bias of the DJIA can be explained primarily by stock dividends and rights issues that have been ignored by the index provider in early years. The other discrepancies generate some noise in the time series but do not have large impacts on the index values. 
Figure 3: Decomposition of Replication Discrepancies of the DJIA

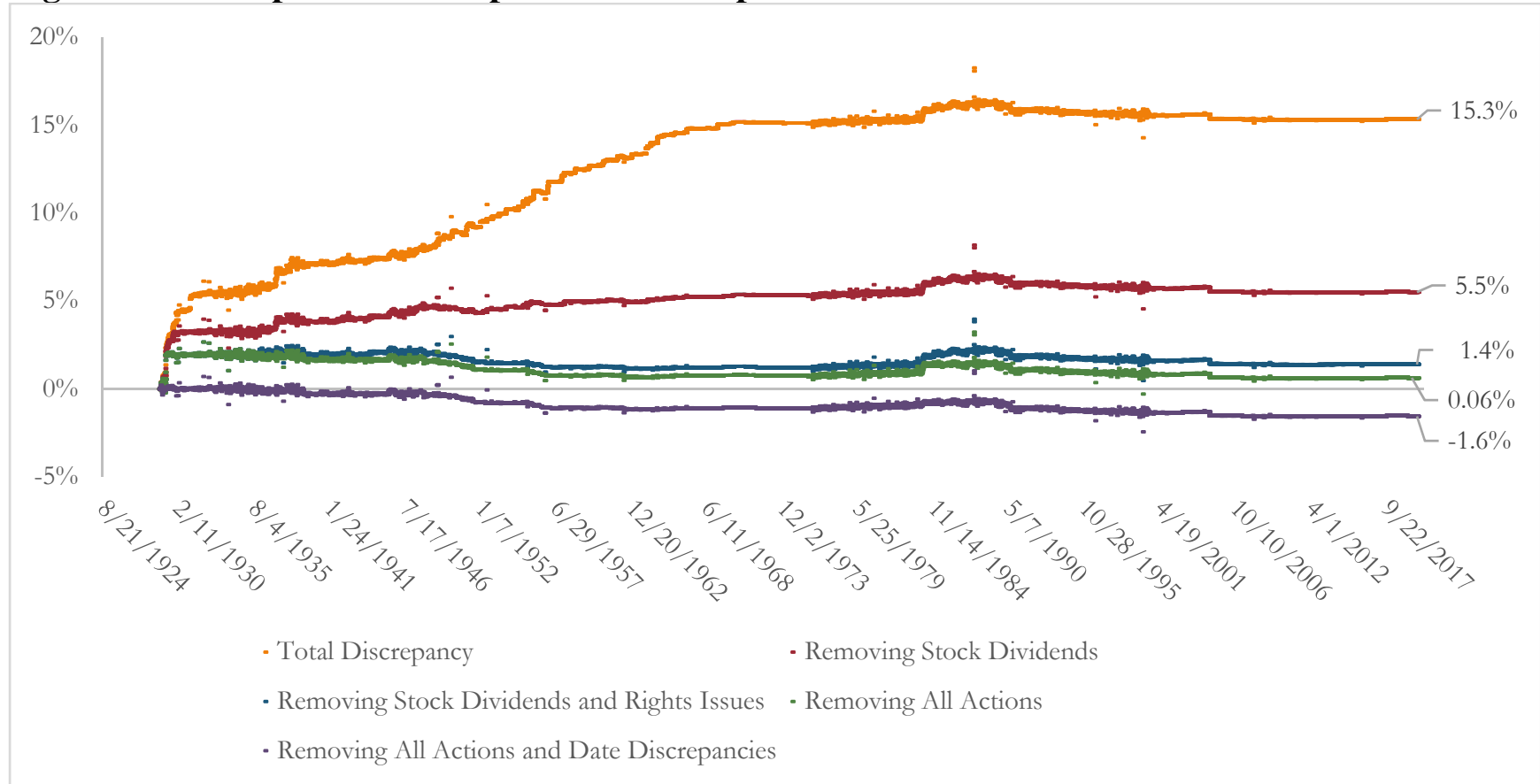

\section{Weighting}

In this section we analyze whether the performance of the DJIA differs from the performance of other indices formed using alternative weighting methods (i.e., price-, value-, and equal-weighted) and alternative compositions (i.e., Dow firms, largest 30 firms, S\&P firms, total market).

\section{A. Different Weighting of Dow Components}

The three main weighting methods for indices are price-, value-, or equal-weighted. Figure 4 depicts the time-series of the three indices using the official membership composition determined by the DJIA. The price-weighted index corresponds to our replicated index that consistently includes stock dividends, rights issues, and other corporate events (i.e., DJIA-R). The valueweighted index (i.e., VW-DJIA) is based on the market capitalizations of the securities at the priorday close. The value-weighted index needs to be rebalanced whenever the composition of the index 
changes or when the number of shares outstanding changes. The equal-weighted index (i.e., EWDJIA) is rebalanced whenever the composition of the DJIA changes and at the end of each calendar year. $^{19}$

\section{Figure 4: Price-, Value-, and Equal-Weighted Index of Dow Components}

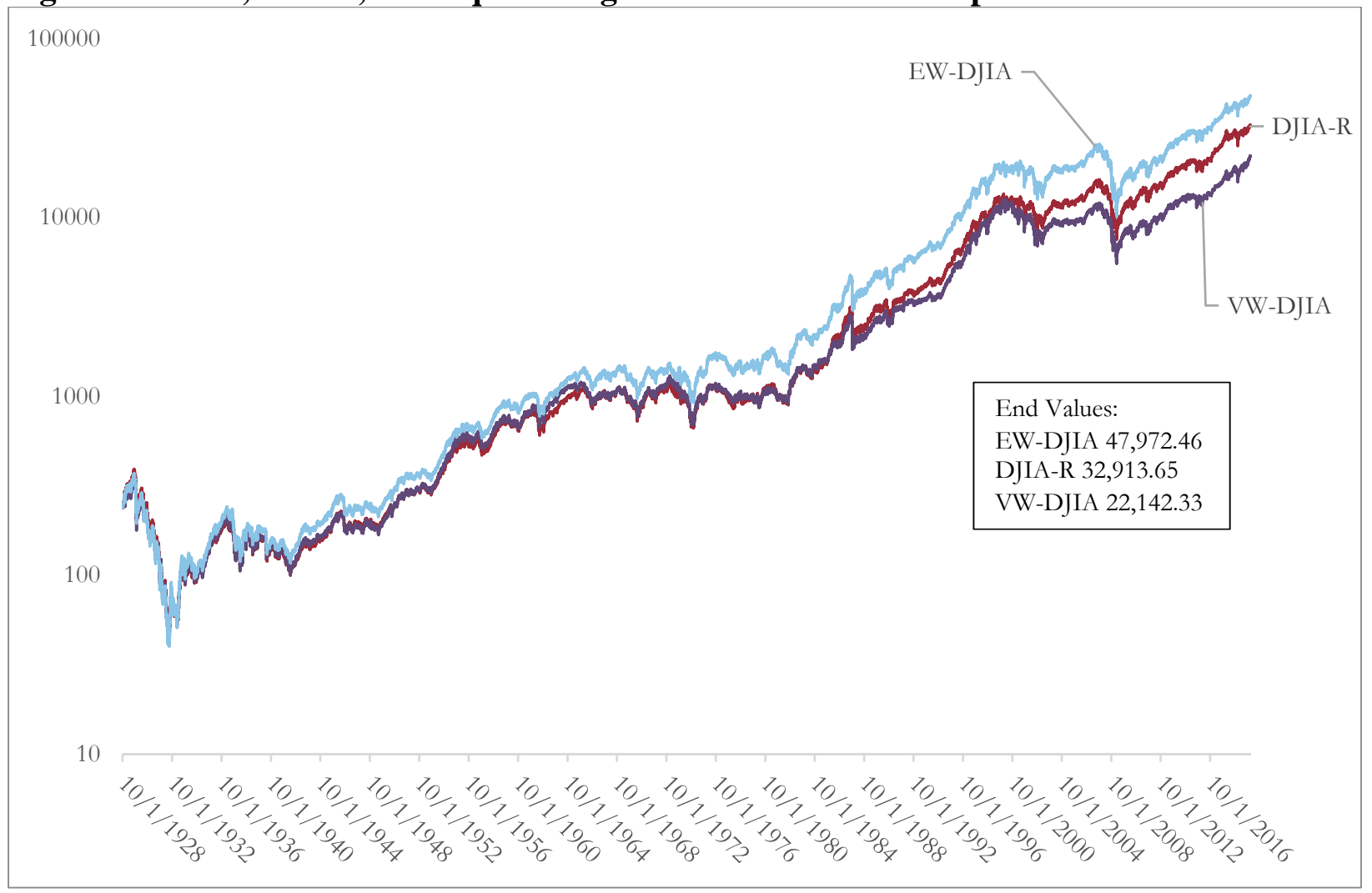

Over our sample period, the equal-weighted index of the Dow components outperforms the priceand value-weighted versions. The end-value of the equal-weighted index is 47,972.46 points, whereas the price- and value-weighted indices closed at 32,913.65 and 22,142.33 points, respectively. The equal-weighted index outperformed the price-weighted index in 49 of the 91

\footnotetext{
${ }^{19}$ The equal-weighted index is not rebalanced daily to avoid biases caused by the bid-ask bounce, microstructure frictions, and data errors. An equal-weighted index needs to purchase securities when the stock price drops and sell securities when the stock price increases. If stock prices bounce from the bid to the ask price, then a daily rebalancing strategy will tend to buy at the bid price and sell at the ask price, which is not possible.
} 
years, whereas the value-weighted index underperformed the price-weighted index in 48 of the 91 years. The paired two-tailed $p$-values are 0.42 for the difference between equal and price weights and 0.11 for the difference between value and price weights. The superior performance of the equal weighted index is related to the small-firm effect first reported by Banz (1981). Even within the relatively large firms in the DJIA, smaller firms tend to outperform larger firms.

\section{B. Different Index Composition}

The companies in the DJIA are not representative of the market as a whole. The components of the DJIA are chosen by the index provider to represent different industries, but they are not chosen according to fixed rules. The index initially included only industrial firms, as indicated by its name. However, the index providers added technology, finance, and consumer goods firms in the 1980s and 1990s to enhance the representativeness of the index. Furthermore, the DJIA includes only 30 relatively large firms. A more representative index would need to include a larger number of companies.

Figure 5 shows the number of firms included in the CRSP database over our sample period. The number of firms publicly listed amounted to only 625 in 1928. The number of publicly-traded firms increased substantially in the 1970s, when NASDAQ was founded. The number reached a maximum of 7,533 in 1997. Since then, the number of publicly-traded firms has declined by more than 50 percent to 3,619.

The representativeness of firms in the DJIA has fluctuated substantially over time. The firms in the DJIA accounted for less than 30 percent of the total market capitalization of publicly-traded 
firms in the late 1920s. The representativeness of these firms increased during the Great Depression and reached more than 40 percent in the early 1940s. The representativeness of the 30 Dow firms deteriorated subsequently as more firms became publicly listed. The 30 firms in the DJIA accounted for 25.9 percent of the market capitalization at the end of 2019.

Figure 5: Representativeness of DJIA and Big-30 Indices

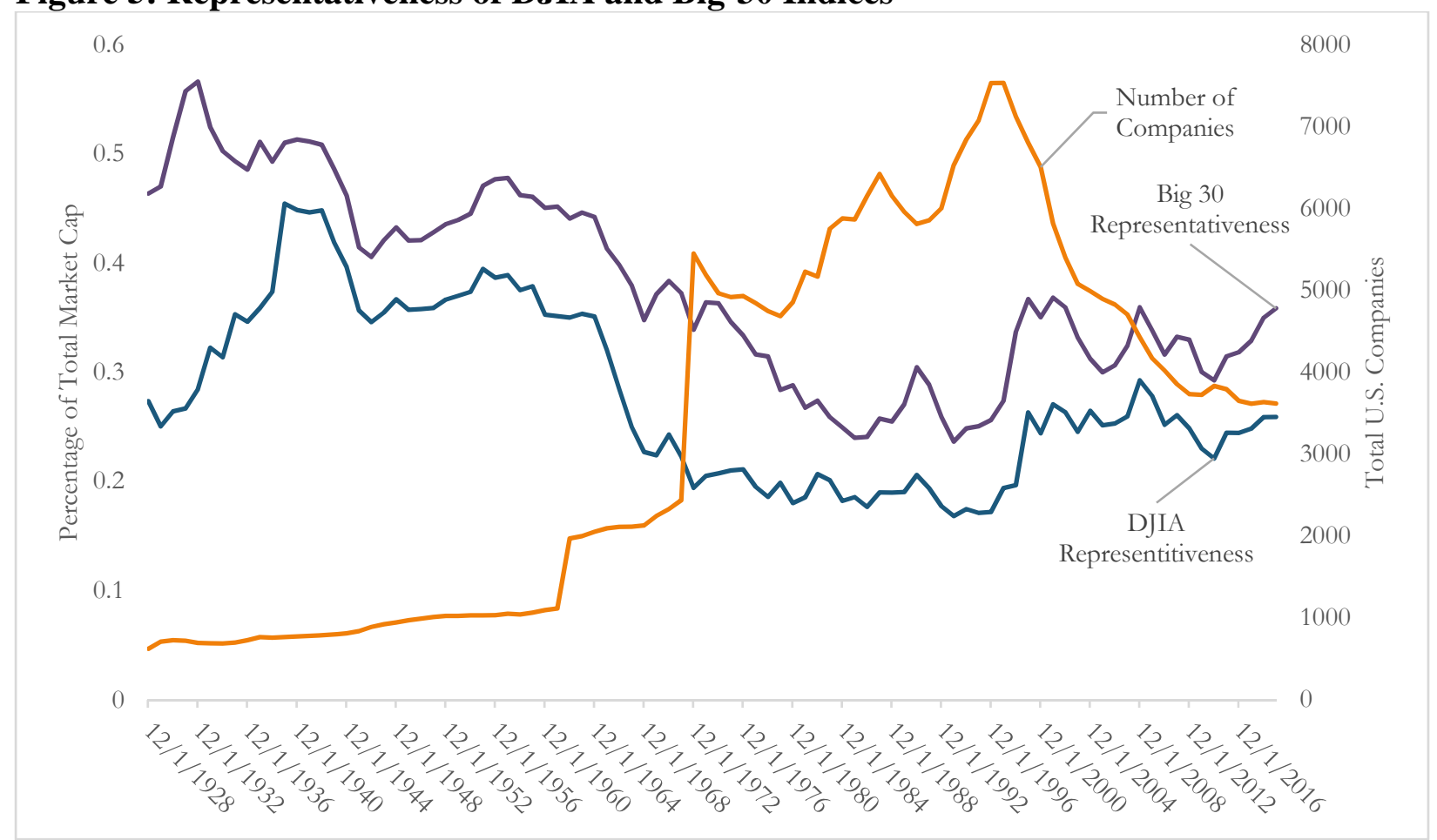

Figure 5 also depicts the representativeness of the 30 largest firms in the CRSP database as measured by market capitalization (i.e., Big 30 index). The representativeness of these largest firms tracks the representativeness of the firms in the DJIA fairly closely. At the end of 2019, the largest 30 firms accounted for 35.9 percent of the total market capitalization of U.S. securities, as measured by the CRSP database. 
Figure 6: Value-Weighted DJIA, Big 30, CRSP Total Market, and S\&P500

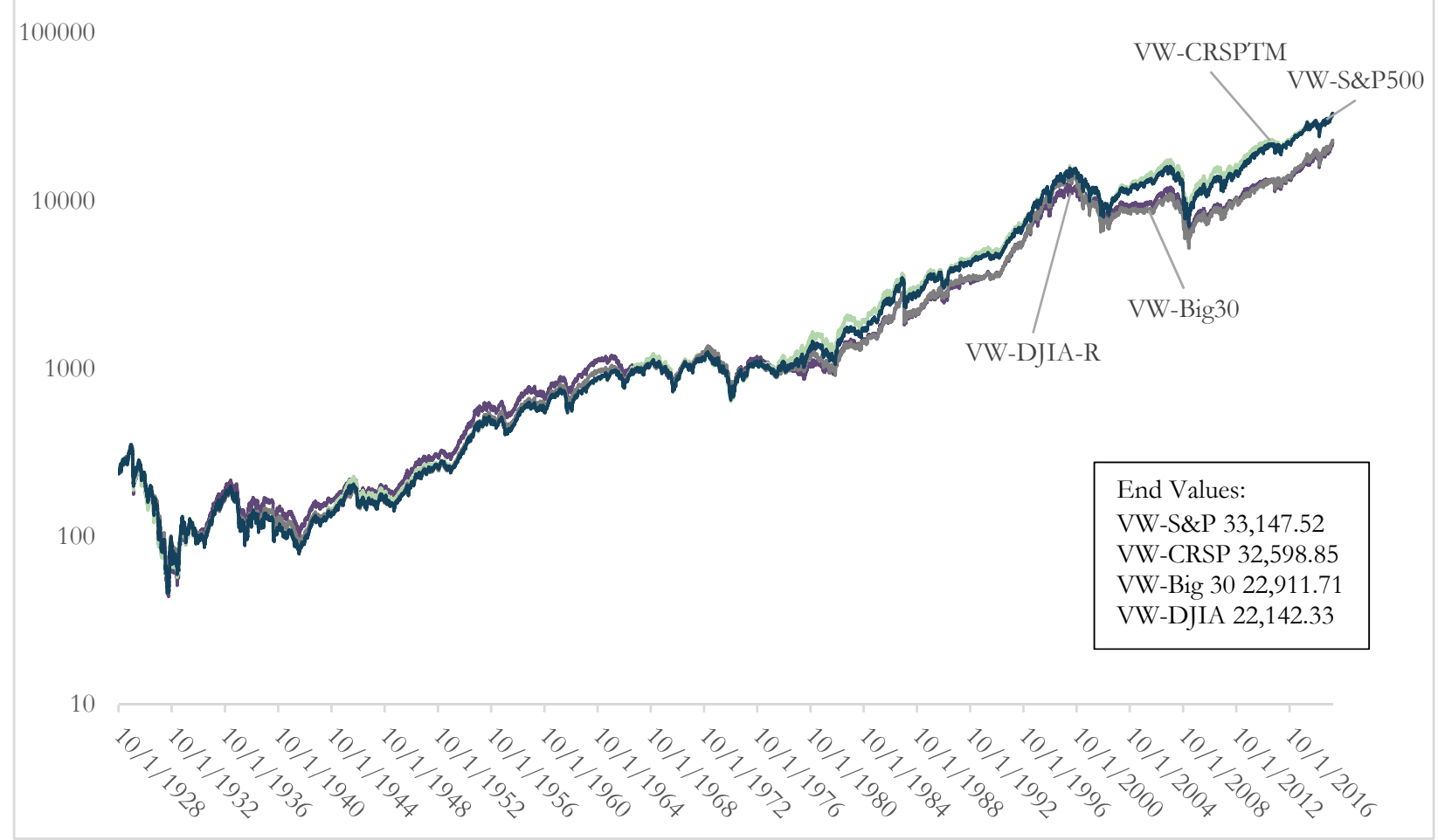

To study the impact of different index compositions, we summarize in Figure 6 the performance of the DJIA, the Big 30 index, the S\&P Composite, and the CRSP total market index, which includes all publicly-traded firms. ${ }^{20}$ To focus on the composition effect, the figure reports the value-weighted versions of the three indices.

The CRSP total market index outperforms both the value-weighted DJIA and the Big-30 index. ${ }^{21}$ Interestingly, the performance of the Big-30 index is almost identical to the performance of the

\footnotetext{
${ }^{20}$ The S\&P Composite Index includes 90 firms until February 28, 1957 and 500 firms subsequently (excluding different share classes). We obtain the daily price and total returns of the S\&P index from CRSP. The values do not exactly correspond to the official S\&P indices, as CRSP replicates the historical index values using their database and the membership composition. For example, the deviation amounts to 1.82 percent from July 1962 to December 2019, when both series are available.

${ }^{21}$ We focus on the value-weighted Big 30 index, as a price-weighted index would be disproportionately weighted towards stocks with high stock prices. For example, at the end of December 2019, a price-weighted Big 30 index would put 97.72 percent of the weight on Berkshire Hathaway, which had at that time a stock price of \$339,590. Apple would only have a weight of 0.08 percent. This example demonstrates that price-weighted indices can be very poorly diversified.
} 
value-weighted DJIA. However, the differences in performance are not statistically significant. The $p$-values for the differences in returns are 0.87 and 0.44 , respectively.

Table 3 summarizes the mean annual price returns, the standard deviations of the annual returns, and the $p$-values for whether the annual returns of the various price indices differ from the published DJIA. ${ }^{22}$ It may be surprising that the long-term performance of the different indices is fairly similar and typically not statistically different from the official DJIA. Over a very long horizon it does not play a significant role how the indices are constructed. The performance of the DJIA is fairly similar to other large-capitalization price-return indices.

It is interesting that the standard deviations are also very similar across the different portfolios. One may have expected broader portfolios to exhibit lower standard deviations due to the superior diversification levels. However, the DJIA tends to include more mature firms that tend to exhibit lower volatilities than younger and smaller firms.

Table 3 also reports the Sharpe ratios of the different price indices. ${ }^{23}$ The Sharpe ratio is lowest for the value-weighted Dow (i.e., 0.177) and highest for the equal-weighted Dow (i.e., 0.217). Broader indices such as the S\&P and the CRSP total market index exhibit higher Sharpe ratios than narrower indices.

\footnotetext{
${ }^{22}$ The annual mean returns, standard deviations, and $p$-values in Tables 3 and 4 exclude the partial year of 1928.

${ }^{23}$ The Sharpe ratio is defined as the annual return of a portfolio in excess of the risk-free rate divided by the annualized standard deviation.
} 
Table 3: End-Values, Mean Annual Returns, Standard Deviations, and P-Values for Different Index Returns

\begin{tabular}{|c|c|c|c|c|c|c|}
\hline Index & $\begin{array}{l}\text { Value on } \\
12 / 31 / 19 \\
\end{array}$ & $\begin{array}{c}\text { Geometric } \\
\text { Mean } \\
\text { Annual } \\
\text { Return } \\
\end{array}$ & $\begin{array}{c}\text { Arithmetic } \\
\text { Mean } \\
\text { Annual } \\
\text { Return } \\
\end{array}$ & $\begin{array}{c}\text { Standard } \\
\text { Deviation } \\
\text { of Annual } \\
\text { Returns } \\
\end{array}$ & $\begin{array}{c}\text { Sharpe } \\
\text { Ratio } \\
\end{array}$ & $\begin{array}{c}\text { P-Value } \\
\text { (Difference } \\
\text { in Mean } \\
\text { Returns to } \\
\text { Published } \\
\text { DJIA) } \\
\end{array}$ \\
\hline Published DJIA & $28,538.44$ & $5.38 \%$ & $6.97 \%$ & $19.03 \%$ & 0.189 & \\
\hline Replicated DJIA & $32,913.65$ & $5.54 \%$ & $7.11 \%$ & $18.98 \%$ & 0.197 & 0.35 \\
\hline VW-DJIA & $22,142.33$ & $5.08 \%$ & $6.78 \%$ & $19.32 \%$ & 0.177 & 0.65 \\
\hline EW-DJIA & $47,972.46$ & $5.98 \%$ & $7.68 \%$ & $19.89 \%$ & 0.217 & 0.04 \\
\hline VW Big 30 & $22,911.72$ & $5.12 \%$ & $6.68 \%$ & $18.24 \%$ & 0.181 & 0.69 \\
\hline S\&P Composite & $33,147.52$ & $5.55 \%$ & $7.28 \%$ & $19.10 \%$ & 0.205 & 0.56 \\
\hline VW CRSPTM & $32,598.85$ & $5.53 \%$ & $7.29 \%$ & $19.28 \%$ & 0.203 & 0.57 \\
\hline Treasury Bills & $4,780.83$ & $3.33 \%$ & $3.37 \%$ & $3.14 \%$ & & 0.08 \\
\hline
\end{tabular}

\section{Cash Dividends}

All the indices considered until now are price indices, which exclude returns from dividend distributions. Although dividend payments generate small return effects for broadly diversified portfolios on a daily basis, these payouts are very important over longer time horizons. ${ }^{24}$ In this section, we study the impact of including cash dividends in stock returns. ${ }^{25}$

\section{A. Dividend Yield}

Figure 7 depicts the annual dividend yield of the price-weighted DJIA over our sample period. The dividend yield is calculated by first determining the price-weighted difference between the total returns and price returns, as defined by CRSP, for each company. These daily price-weighted return differences are then summed up over a calendar year to calculate the annual dividend yield.

\footnotetext{
${ }^{24}$ The DJIA has included four special dividends by adjusting the divisor. These dividend payments were the \$39.625 special dividend by Union Carbide (UK) in 1986, the \$4 and \$3 special dividends of Texaco (TX) in 1989, and the \$3 special dividend by Microsoft (MSFT) in 2004.

${ }^{25}$ S\&P Dow Jones Indices computes a total return index for the DJIA starting on September 30, 1987.
} 
The average dividend yield of the DJIA from 1929-2019 equals 3.86 percent. The dividend yield has decreased substantially since the early 1980s as firms partially substituted share repurchases for dividends.

Figure 7: Dividend Yield of DJIA, Big 30, and CRSP Total Market Indices

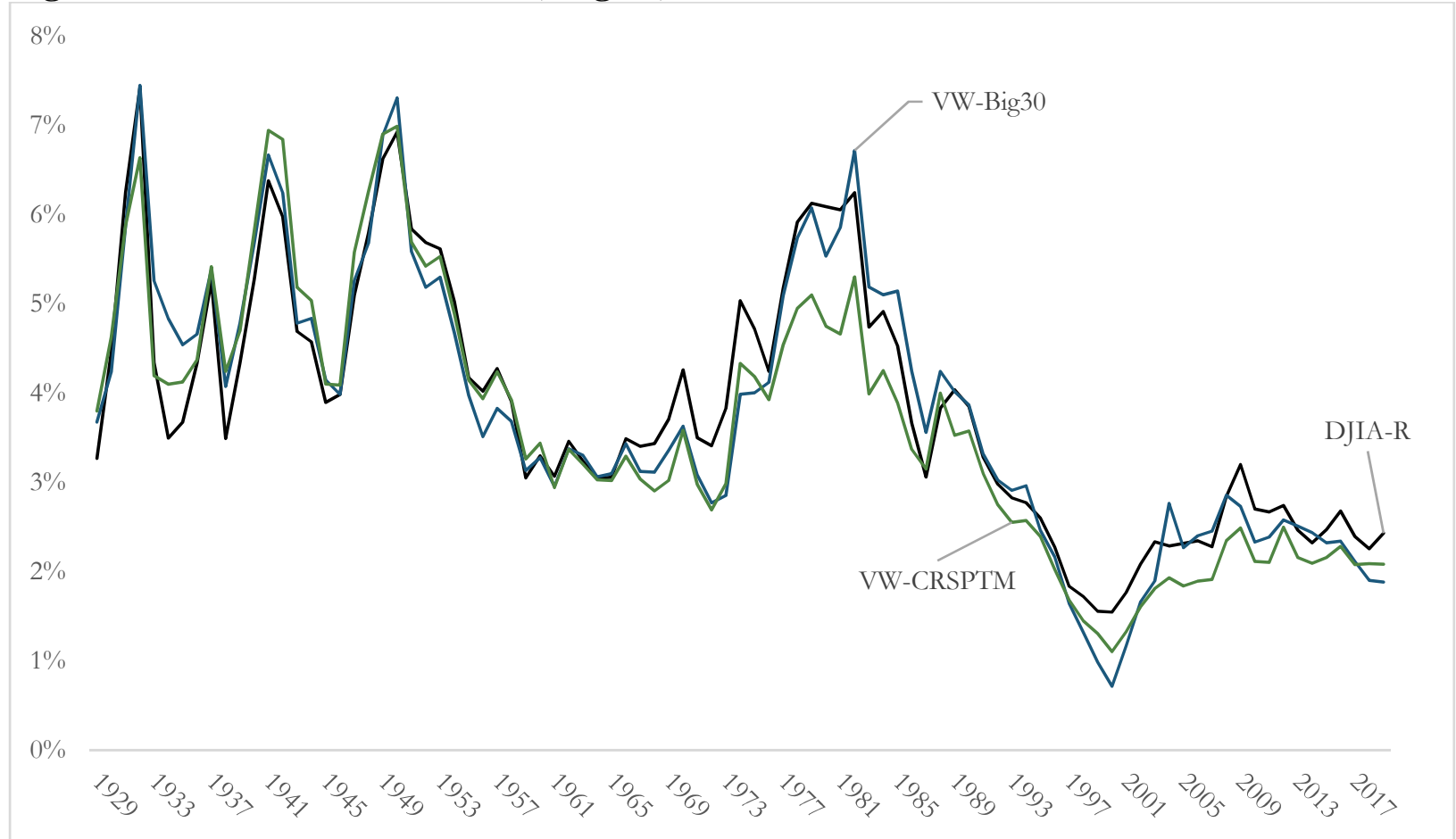

\section{B. Index Values with Dividend Payments}

To incorporate the returns of dividend payments to the index values, we recursively compute the price-weighted total return index by including the dividend payments on a daily basis. The initial value is set equal to the value of the DJIA at the beginning of October 1928.

$$
P W T R I_{t}=P W T R I_{t-1} \sum_{i} w_{i, t} \frac{P_{i, t}+D_{i, t}}{P_{i, t-1}} \text {, where } w_{i, t}=\frac{P_{i, t-1}}{\sum_{i} P_{i, t-1}} .
$$




\section{Figure 8: Price-Weighted DJIA with and without Dividends}

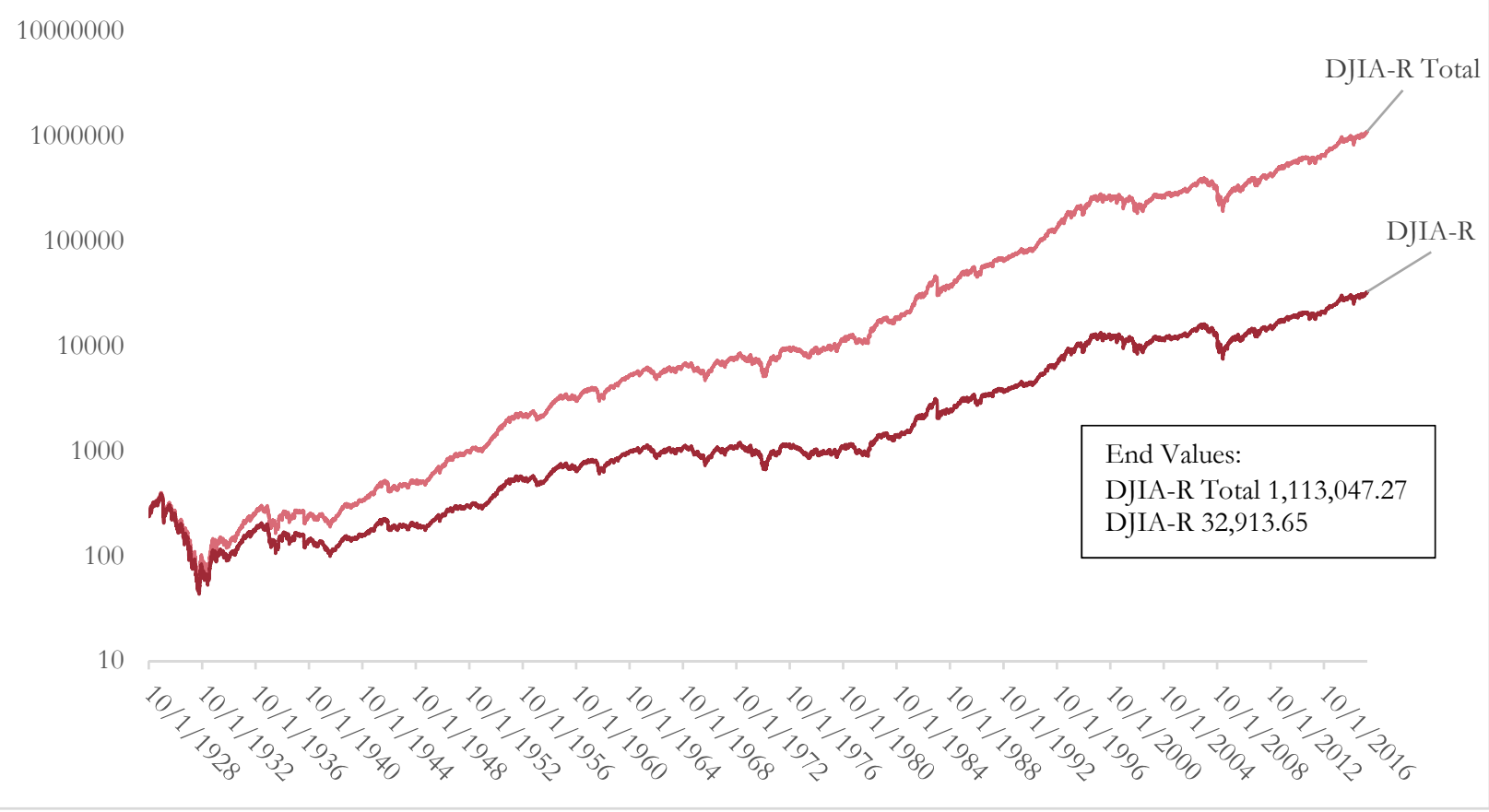

Whereas the other adjustments discussed earlier in our paper have small or moderate impacts on the indices, adjusting for dividends has an enormous impact on the accumulated value for longterm strategies when those dividends are reinvested. The replicated DJIA without dividend payments accumulated to 32,914 points by the end of 2019. On the other hand, including dividend payments and reinvesting those dividend payments back into the index increase the index level by 34 times to 1,113,047 points. Thus, ignoring dividend payments understates the performance of long-term stock investors dramatically.

\section{Alternative Weighting Methods}

Our final analyses compute the total return indices using different weighting methods and index compositions. 
Figure 9 summarizes the time-series patterns of the price-, value-, and equal-weighted indices of the Dow components. Consistent with our prior analysis based on price returns, we find that the equal-weighted index outperforms the price-weighted index and the value-weighted index underperforms the price-weighted index. The end values are 1,820,443 points for the equalweighted return and 881,297 for the value-weighted return.

Figure 9: Price-, Value-, and Equal-Weighted Total Return Indices of DJIA Components with Dividends

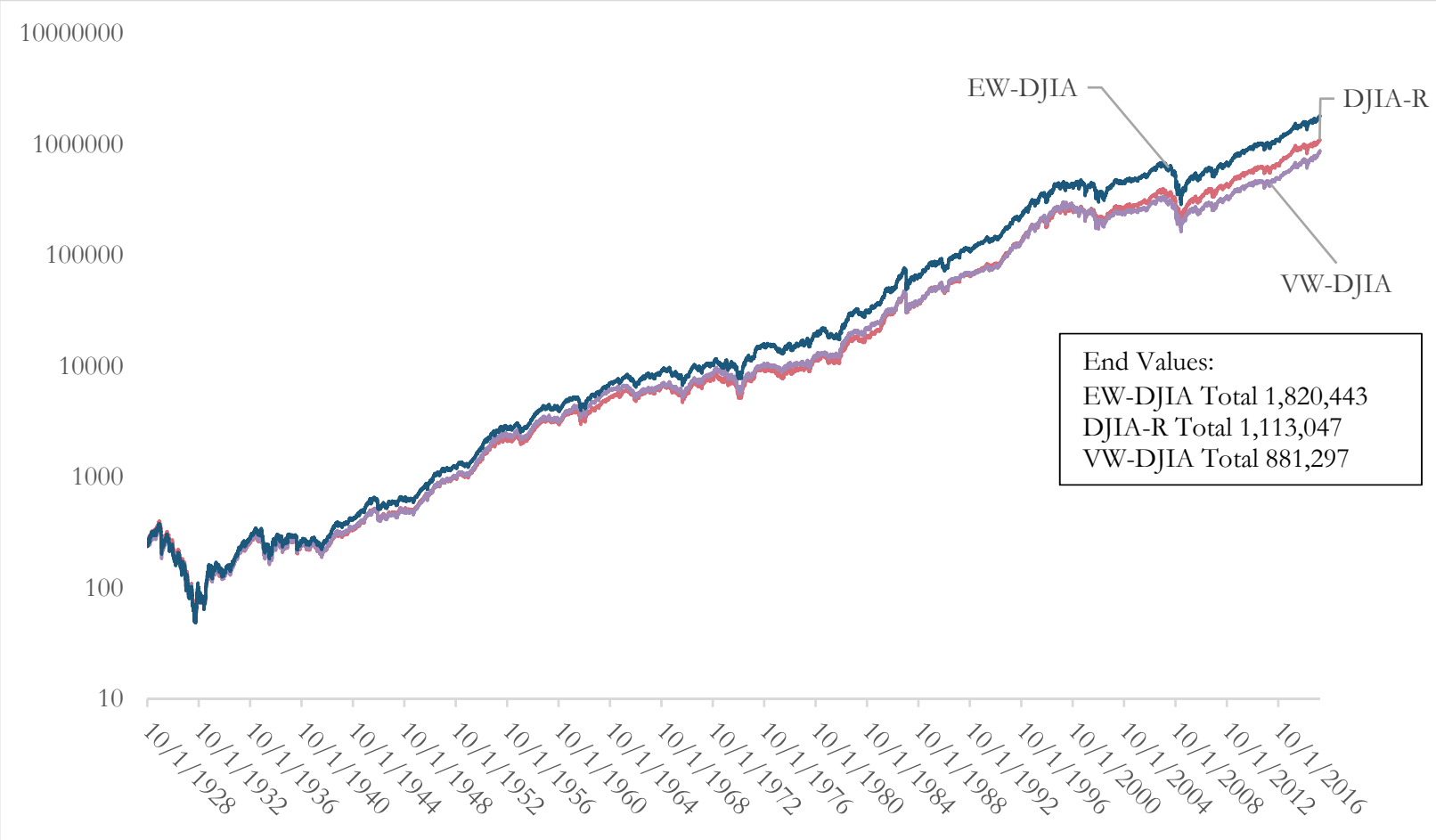

Figure 10 studies the impact of different index membership. To focus on the composition effects, we depict the performance of the value-weighted versions of the indices. The value-weighted S\&P Composite index exhibits the highest performance level and closes at a value of 1,021,118 at the end of 2019. On the other hand, the Big-30 index exhibits the worst long-term performance. 
Figure 10: DJIA, Big 30, CRSP, and S\&P 500 Indices with Dividends

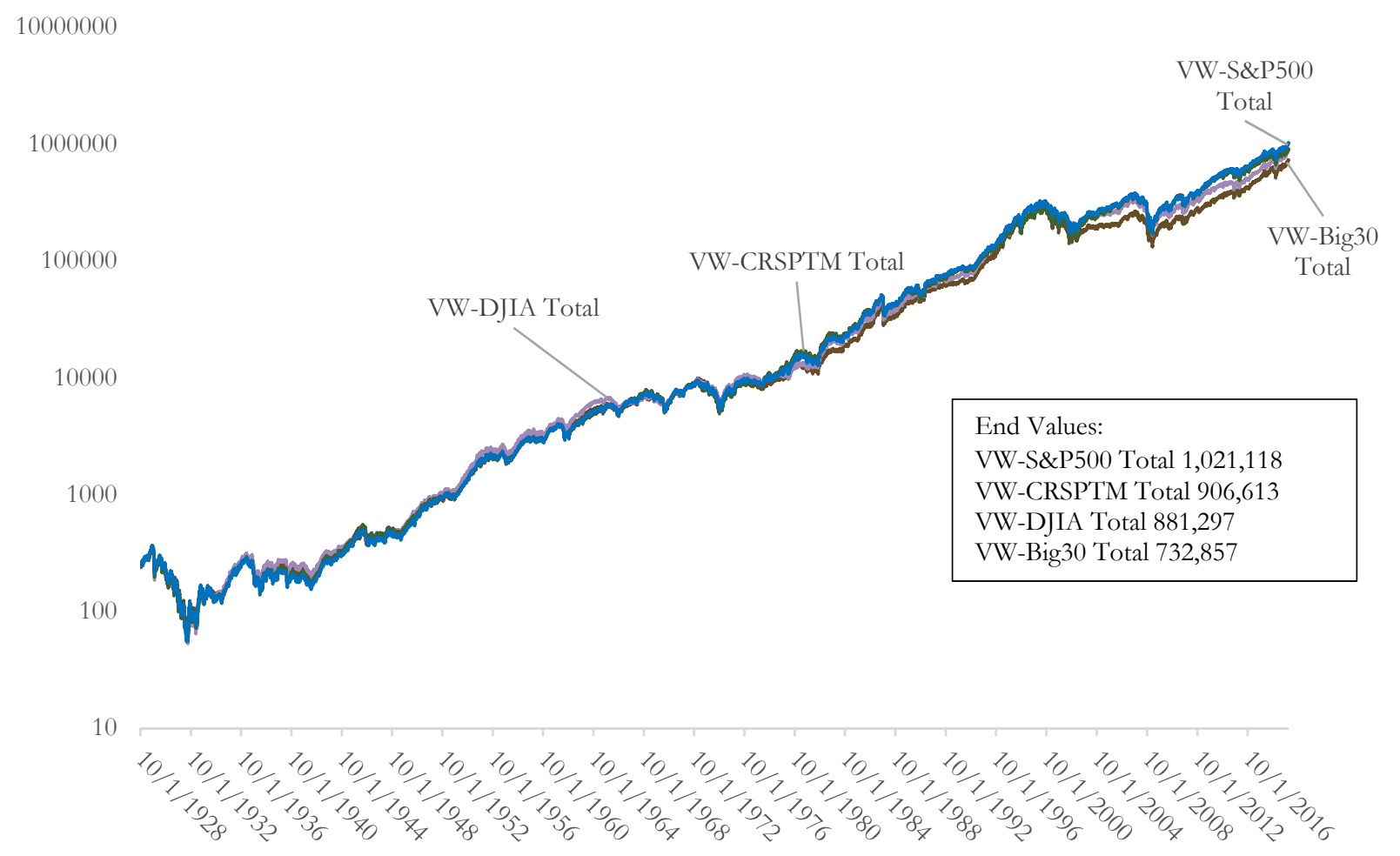

Table 4 reports the summary statistics for the long-term performance of the total returns of the different indices. The last column indicates that the mean total returns for all stock indices except for the equal-weighted DJIA are not statistically significantly different from the total-return DJIA. The Sharpe ratios are also fairly close to the one for the DJIA. Thus, weighting methods and membership composition are of second order, whereas the inclusion of dividends is a first order effect. 
Table 4: End-Values, Mean Annual Returns, Standard Deviations, and P-Values for Different Index Returns with Dividends

\begin{tabular}{|l|r|r|r|r|r|r|}
\hline & Value on & $\begin{array}{c}\text { Geometric } \\
\text { Mean } \\
\text { Innual } \\
\text { Return }\end{array}$ & $\begin{array}{c}\text { Arithmetic } \\
\text { Mean } \\
\text { Annual } \\
\text { Return }\end{array}$ & $\begin{array}{c}\text { Standard } \\
\text { Deviation } \\
\text { of } \\
\text { Annual } \\
\text { Returns }\end{array}$ & $\begin{array}{c}\text { P-Value } \\
\text { Sharpe } \\
\text { Ratio }\end{array}$ & $\begin{array}{c}\text { Difference } \\
\text { in Mean } \\
\text { Returns to } \\
\text { DJIA-R) }\end{array}$ \\
\hline DJIA-R & $1,113,047.27$ & $9.69 \%$ & $11.28 \%$ & $19.57 \%$ & 0.404 & \\
VW-DJIA & $881,296.81$ & $9.41 \%$ & $11.15 \%$ & $19.99 \%$ & 0.389 & 0.75 \\
EW-DJIA & $1,820,442.71$ & $10.29 \%$ & $12.02 \%$ & $20.50 \%$ & 0.422 & 0.05 \\
VW-Big30 & $732,856.67$ & $9.19 \%$ & $10.78 \%$ & $18.82 \%$ & 0.394 & 0.48 \\
S\&P Composite & $1,021,117.92$ & $9.59 \%$ & $11.36 \%$ & $19.74 \%$ & 0.405 & 0.89 \\
VW-CRSPTM & $906,612.62$ & $9.45 \%$ & $11.24 \%$ & $19.89 \%$ & 0.396 & 0.94 \\
Treasury Bills & $4,780.83$ & $3.33 \%$ & $3.37 \%$ & $3.14 \%$ & & 0.00 \\
\hline
\end{tabular}

\section{Conclusions}

We discuss in this paper the unique features of the DJIA. It uses price weights, it ignores cash dividend payments, and it also treats stock dividends, rights issues, and other corporate actions inconsistently. We replicate the DJIA and show that alternative stock price indices that use superior weighting methods and more systematic inclusion criteria perform very similarly to the Dow Jones Industrial Average. However, ignoring cash and stock dividends underestimates the long-run returns earned by stock market investors dramatically.

Our work suggests that publicizing a value weighted, broadly defined, total return index which includes dividend payments of stocks would be useful for gauging the returns offered by U.S. equity markets. Such an index could be continuously computed and might aid people in making their own portfolio decisions. 


\section{References}

Arora, Anita, Lauren Capp, and Gary Smith (2008). “The Real Dogs of the Dow,” The Journal of Wealth Management, 10 (4), 64-72.

Banz, Rolf W. (1981). “The Relationship between Return and Market Value of Common Stocks,” Journal of Financial Economics, 9 (1), 3-18.

Butler, Hartman L. and Martin G. Decker (1953) "A Security Check on the Dow-Jones Industrial Average,” The Financial Analysts Journal, 9 (1), 37-45.

Clarke, Roger G. and Meir Statman (2000). “The DJIA Crossed 652,230. In 1998,” The Journal of Portfolio Management, 26 (2), 89-93.

Comer, Harry D. (1952). “The Market-Looking Backward,” The Financial Analysts Journal, 8 (4), 143-144.

Dow Jones (2000). "The Dow Jones Averages: History of Divisor Changes For the Period from 11/05/1928 to 12/31/1999,” Dow Jones \& Company.

Hartzmark, Samuel M. and David Solomon (2019). “The Dividend Disconnect.” Journal of Finance 74 (5), 2153-2199.

Hartzmark, Samuel M. and David Solomon (2020). "Reconsidering Returns." Forthcoming: Review of Financial Studies.

Ibbotson Associates (2000). “Stocks, Bonds, Bills, and Inflation,” Chicago: Ibbotson Associates.

Milne, Robert D. (1966). “The Dow-Jones Industrial Average Re-Examined,” The Financial Analysts Journal, 22 (6), 83-88.

Pierce, Phyllis S. (Editor) (1996). “The Dow Jones Averages 1885-1995,” Chicago: Irwin.

Rudd, Andrew T. (1979). “The Revised Dow Jones Industrial Average: New Wine in Old Bottles?” The Financial Analysts Journal, 35 (6), 57-63.

Shaw, Robert B. (1955). “The Dow-Jones Industrials vs. the Dow-Jones Industrial Average,” The Financial Analysts Journal, 11 (5) (November 1955), 37-40.

Shoven, John B. and Clemens Sialm (2000). “The Dow Jones Industrial Average: The Impact of Fixing Its Flaws,” The Journal of Wealth Management, 3 (3), 9-18.

Siegel, Jeremy J. (1998). “Stocks for the Long Run,” New York: McGraw-Hill (2 ${ }^{\text {nd }}$ edition).

S\&P Dow Jones Indices (2021). “Dow Jones Averages Methodology.”

Williamson, Samuel H. (2000), "Daily Closing Values of the DJA in the United States, 1885 to Present." Measuring Worth (http://www.measuringworth.com/DJA/). 


\section{Appendix}

Table A1: Components of DJIA on December 31, 2019

\begin{tabular}{|c|c|c|c|c|c|}
\hline Ticker & Price & $\begin{array}{c}\text { Shares } \\
\text { outstanding } \\
\text { (millions) }\end{array}$ & $\begin{array}{c}\text { Market cap } \\
\text { (billions) }\end{array}$ & Price weight & Market weight \\
\hline AAPL & 293.65 & 4,443 & 1,305 & $6.98 \%$ & $15.90 \%$ \\
\hline MSFT & 157.70 & 7,632 & 1,204 & $3.75 \%$ & $14.67 \%$ \\
\hline JPM & 139.40 & 3,136 & 437 & $3.31 \%$ & $5.33 \%$ \\
\hline $\mathrm{JNJ}$ & 145.87 & 2,632 & 384 & $3.47 \%$ & $4.68 \%$ \\
\hline WMT & 118.84 & 2,837 & 337 & $2.82 \%$ & $4.11 \%$ \\
\hline $\mathrm{V}$ & 187.90 & 1,712 & 322 & $4.47 \%$ & $3.92 \%$ \\
\hline PG & 124.90 & 2,494 & 311 & $2.97 \%$ & $3.80 \%$ \\
\hline XOM & 69.78 & 4,231 & 295 & $1.66 \%$ & $3.60 \%$ \\
\hline UNH & 293.98 & 947 & 279 & $6.99 \%$ & $3.39 \%$ \\
\hline DIS & 144.63 & 1,802 & 261 & $3.44 \%$ & $3.18 \%$ \\
\hline INTC & 59.85 & 4,350 & 260 & $1.42 \%$ & $3.17 \%$ \\
\hline VZ & 61.40 & 4,136 & 254 & $1.46 \%$ & $3.10 \%$ \\
\hline HD & 218.38 & 1,091 & 238 & $5.19 \%$ & $2.90 \%$ \\
\hline $\mathrm{KO}$ & 55.35 & 4,284 & 237 & $1.32 \%$ & $2.89 \%$ \\
\hline MRK & 90.95 & 2,546 & 232 & $2.16 \%$ & $2.82 \%$ \\
\hline CVX & 120.51 & 1,891 & 228 & $2.86 \%$ & $2.78 \%$ \\
\hline PFE & 39.18 & 5,534 & 217 & $0.93 \%$ & $2.64 \%$ \\
\hline CSCO & 47.96 & 4,242 & 203 & $1.14 \%$ & $2.48 \%$ \\
\hline BA & 325.76 & 563 & 183 & $7.74 \%$ & $2.23 \%$ \\
\hline MCD & 197.61 & 753 & 149 & $4.70 \%$ & $1.81 \%$ \\
\hline UTX & 149.76 & 863 & 129 & $3.56 \%$ & $1.58 \%$ \\
\hline NKE & 101.31 & 1,246 & 126 & $2.41 \%$ & $1.54 \%$ \\
\hline IBM & 134.04 & 886 & 119 & $3.19 \%$ & $1.45 \%$ \\
\hline $\mathrm{AXP}$ & 124.49 & 818 & 102 & $2.96 \%$ & $1.24 \%$ \\
\hline MMM & 176.42 & 575 & 101 & $4.19 \%$ & $1.24 \%$ \\
\hline CAT & 147.68 & 553 & 82 & $3.51 \%$ & $0.99 \%$ \\
\hline GS & 229.93 & 354 & 81 & $5.46 \%$ & $0.99 \%$ \\
\hline WBA & 58.96 & 888 & 52 & $1.40 \%$ & $0.64 \%$ \\
\hline DOW & 54.73 & 741 & 41 & $1.30 \%$ & $0.49 \%$ \\
\hline TRV & 136.95 & 258 & 35 & $3.25 \%$ & $0.43 \%$ \\
\hline
\end{tabular}

